\title{
Correction to: Role of growth factors in hematopoietic stem cell niche
}

\author{
Dabin Lee • Dong Wook Kim • Je-Yoel Cho $\mathbb{D}$
}

Published online: 9 November 2020

(C) Springer Nature B.V. 2020

\section{Correction to: Cell Biol Toxicol (2020) 36:131-144 https://doi.org/10.1007/s10565-019-09510-7}

Unfortunately, this article is posted online with missing acknowledgement section.

The missing acknowledgement statement is shown below.
Acknowlegement: This article was supported by the Bio \& Medical Technology Development Program of the National Research Foundation (NRF) funded by the Ministry of Science and ICT(2014M3A9D5A01073598) (\#2016M3A9B6026771).

Publisher's note Springer Nature remains neutral with regard to jurisdictional claims in published maps and institutional affiliations.
The online version of the original article can be found at https://doi.org/10.1007/s10565-019-09510-7

D. Lee · D. W. Kim · J.-Y. Cho $(\bowtie)$

Department of Biochemistry, BK21 PLUS Program for Creative Veterinary Science Research and Research Institute for Veterinary Science, College of Veterinary Medicine, Seoul National University, 1 Gwanak-ro, Gwanak-gu, Seoul 151-742, South

Korea

e-mail: jeycho@snu.ac.kr 